\title{
Open System Analysis of Bioextracted Iron during Leaching of Iron Oxide Ore using Acidithiobacillus Ferrooxidans
}

\author{
E. M. Ameh ${ }^{1}$, I. D. Adiele ${ }^{2}$, C. A. Mgbachi ${ }^{3}$, S. I. Neife ${ }^{4}$, S. E. Ede ${ }^{1}$, \\ A. O. Agbo and E. E. Nnuka ${ }^{5}$ \\ ${ }^{I}$ Department of Metallurgical and Materials Engineering, Enugu State University of Science \\ \& Technology, Enugu, Nigeria \\ ${ }^{2}$ Projects Development Institute (PRODA), Enugu, Nigeria \\ ${ }^{3}$ Department of Computer Science Engineering, Enugu State University of Science \& Technology, Enugu, Nigeria \\ ${ }^{4}$ Department of Metallurgical and Materials Engineering, University of Nigeria, Nsukka, Nigeria \\ ${ }^{5}$ Department of Metallurgical and Materials Engineering, Nnamdi Azikiwe University, Awka, Nigeria
}

\begin{abstract}
This paper presents an open systemic analysis of bioextracted iron during leaching of iron oxide ore using acidithiobacillus ferrooxidans. The analysis showed prediction of the concentration of bioextracted iron at varying initial bioleaching solution $\mathrm{pH}$ and as-beneficiated Fe content of the ore. An empirical model was derived, validated and used as a tool for the analysis. The validity of the polynomial model expressed as;

$\zeta=0.0077 \vartheta^{3}-0.1618 \vartheta^{2}+0.9345 \vartheta+0.0002 \vartheta+0.0931$

was found to be rooted on the core expression $\zeta-0.0002,-0.0931=0.0077 \vartheta^{3}-0.1618 \vartheta^{2}+0.9345 \vartheta$ where both sides of the expression are correspondingly approximately equal. Statistical analysis of the extracted iron concentration as obtained from experiment and derived model for each value of the initial bioleaching solution pH used shows standard errors of 0.3917 and 0.3780 respectively. Extracted iron concentrations per unit initial bioleaching solution $\mathrm{pH}$ as obtained from experiment and derived model are 0.0917 and $0.0784 \%$. Deviational analysis indicates that the maximum deviation of the model-predicted iron extraction (from experimental results) was less than $11 \%$, implying a confidence level above $89 \%$.
\end{abstract}

Keywords: Open system Analysis, Iron Bioextraction, Iron Ore Leaching, Acidithiobacillus Ferrooxidans.

\section{Introduction}

Extraction of metal from its ore through hydrometallurgy has been widely recognized and accepted to be significantly environmental friendly. Intensive researches are unavoidably necessary to review this potentiality and also explore ways of improving on hydrometallurgical techniques that would ensure optimum results.

The dissolution of iron oxide is believed to take place via a photo-electro chemical reduction process, involving a complicated mechanism of charge transfer between the predominant oxalate species, namely ferric oxalate $\mathrm{Fe}\left(\mathrm{C}_{2} \mathrm{O}_{4}\right)_{3}{ }^{3-}$, ferrous oxalate $\mathrm{Fe}\left(\mathrm{C}_{2} \mathrm{O}_{4}\right)_{2}{ }^{2-}$ acting also as an auto catalyst, and the oxalate ligand on the iron oxide surface [1]. The dissolution of iron oxides in oxalic acid was found to be very slow at temperatures within the range $25-60 \mathrm{oC}$, but its rate increases rapidly above $90 \mathrm{oC} \mathrm{[2].} \mathrm{The} \mathrm{dissolution} \mathrm{rate} \mathrm{also} \mathrm{increases} \mathrm{with}$ increasing oxalate concentration at the constant $\mathrm{pH}$ values set within the optimum range of $\mathrm{pH}$ 2.5-3.0. At this optimum $\mathrm{pH}$, the dissolution of fine pure haematite $\left(\mathrm{Fe}_{2} \mathrm{O}_{3}\right)(105-140 \mu \mathrm{m})$ follows a diffusion-controlled shrinking core model [2]. Taxiarchour et al [3] reported that it took close to 40h to dissolve $80 \%$ of pure haematite slurry (97\% purity, $0.022 \% \mathrm{w} / \mathrm{v}$ or $0.21 \% \mathrm{~g} / \mathrm{L} \mathrm{Fe}_{2} \mathrm{O}_{3}$ ) at $\mathrm{pH} 1$. He stated that even at $900 \mathrm{C}$, it required close to $10 \mathrm{~h}$ to achieve $95 \%$ dissolution of iron of the slurry at $\mathrm{pH} 1$. They also dissolved iron using $0.1-0.5 \mathrm{M}$ oxalic acid (pH1-5) to dissolve iron from a $20 \% \mathrm{w} / \mathrm{v}$ slurry $(83 \%$ of particle size in the range $0.18-0.35 \mathrm{~mm}$, containing $0.029 \% \mathrm{Fe}_{2} \mathrm{O}_{3}$ ). The iron oxide concentration in the leach is equivalent to $0.058 \mathrm{~g} / \mathrm{L} \mathrm{Fe} 2 \mathrm{O} 3$.

The speciation of $\mathrm{Fe}(\mathrm{III})$ oxalate and $\mathrm{Fe}$ (II) oxalate has been found [4] to be governed by $\mathrm{pH}$ and total oxalate concentration. For a having $\mathrm{pH}>2.5$ and an oxalate concentration higher than $0.1 \mathrm{M}$, the most predominant $\mathrm{Fe}$ (III) complex ion existing is $\mathrm{Fe}\left(\mathrm{C}_{2} \mathrm{O}_{4}\right)_{3}{ }^{-3}$. At these conditions, $(\mathrm{pH}>2.5$ and an oxalate concentration higher than $0.1 \mathrm{M})$ the predominant $\mathrm{Fe}(\mathrm{II})$ complex species is $\mathrm{Fe}\left(\mathrm{C}_{2} \mathrm{O}_{4}\right)_{2}{ }^{-2}$.

Lee et al. [5] reported that the leaching of $3 \mathrm{~g} / \mathrm{L}$ pure haematite $(98.2 \%$ purity, $105-140 \mu \mathrm{m}$ size range) using $0.048-0.48 \mathrm{M}$ oxalic acid at $80-1000 \mathrm{C}$ passed through a maximum peak at $\mathrm{pH} 2.5$. Dissolution of

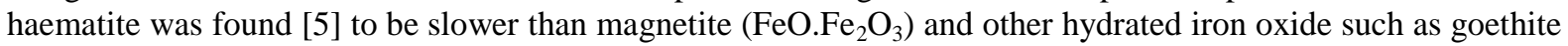
$(\alpha-\mathrm{FeOOH})$, lapidochrosite $(\gamma-\mathrm{FeOOH})$ and iron hydroxide $\left(\mathrm{Fe}(\mathrm{OH})_{3}\right)$.

The presence of $\mathrm{Fe}^{2+}$ was found to significantly enhance the leaching of iron extraction from silica sand at a temperature even as low as $25^{\circ} \mathrm{C}$ [3]. Ferrous oxalate however is oxidized quickly by air during the dissolution and in general an induction period of a few hours was observed to exist unless a strong acidic 
environment $(<\mathrm{pH} 1)$ or an inert atmosphere is maintained. Maintaining the high level of ferrous oxalate in the leach liquor using an inert gas, was found [3] to enhance the reaction kinetics. Intensive researches have been conducted on the dissolution of goethite in several inorganic acids belonging to the families of the carboxylic and diphosphoric acids in the presence of reducing agents

Analysis of results generated from these extraction processes has been carried using various derived models which functioned as tools. A model for the evaluation of the concentrations of dissolved iron (relative to the final solution $\mathrm{pH}$ and temperature) during leaching of iron oxide ore in sulphuric acid solution has been derived [6]. The model

$$
\% \mathrm{Fe}=0.35(\alpha / \mathrm{T})^{3}
$$

Depended on the values of the final $\mathrm{pH}$ and temperature of the leaching solution which varied with leaching time. The positive and negative deviations of the model-predicting values of $\% \mathrm{Fe}$ (dissolved) from those of the experimental values were found to be within the range of acceptable deviation limit for experimental results.

Calculations of the concentrations of leached iron during leaching of iron oxide ore in sulphuric acid solution has been achieved through application of a model [7]. The model is expressed as

$$
\% \mathrm{Fe}=\mathrm{e}^{-2.0421(\mathrm{nnT})}
$$

The predicted concentrations of leached Fe were observed to be very close to the values obtained from the experiment. The model shows that the concentrations of leached Fe were dependent on the values of the final leaching solution temperature measured during the leaching process. It was observed that the validity of the model is rooted in the expression $\ln (\% \mathrm{Fe})=\mathrm{N}(\mathrm{InT})$ where both sides of the expression are correspondingly approximately equal.

A model was successfully derived for predictive analysis of the concentrations of dissolved iron during leaching of iron oxide ore in sulphuric acid solution [8].The model expressed as

$$
\% \mathrm{Fe}=0.987(\mu / \mathrm{T})
$$

Was able to predict the concentrations of dissolved Fe with a high degree of precision. It was observed that the model was dependent on the values of the leaching temperature and weight of iron oxide ore added. The validity of the model was found to be rooted in the expression $\% \mathrm{Fe}=\mathrm{N}(\mu / \mathrm{T})$ where both sides of the relationship are correspondingly approximately equal. The maximum deviation of the model-predicted concentration of dissolved $\mathrm{Fe}$ from those of the experimental values was found to be less than $19 \%$ which is quite within the acceptable range of deviation limit for experimental results, hence depicting the usefulness of the model as a tool for predictive analysis of the dissolved iron during the process.

The aim of this work is to take an open system analysis of bioextracted iron during leaching of iron oxide ore using acidithiobacillus ferrooxidans. The essence of this work is to predict the concentration of $\mathrm{Fe}$ bioextraction achievable at different initial bioleaching solution $\mathrm{pH}$ where all other input process parameters are kept constant.

\section{Materials And Methods}

Agbaja (Nigeria) iron ore concentrate used for this work was obtained from Nigeria Metallurgical Development Centre (NMDC) Jos. The concentrate was dried in air (under atmospheric condition) and used in the as-received condition. Five samples of constant weight quantity of the dried iron ore concentrate of particle size 0.25 mesh size were each added to a culture of ATF in a conical flask and the mixtures (each with $\mathrm{pH} 1.0$ ) allowed to react for 2 weeks at a temperature of $25^{\circ} \mathrm{C}$ after which the mixtures were filtered and the concentration of bioextracted $\mathrm{Fe}$ determined using atomic absorption spectrometer (AAS). The average of the bioextracted $\mathrm{Fe}$ concentration determined in each experiment set was taken as the precise result. The experiment was repeated with different initial bioleaching solution $\mathrm{pHs} ; 2,4,7$ and 9 and the corresponding bioextracted $\mathrm{Fe}$ also determined using AAS. Details of the experimental procedures and process conditions prevailing during the biooxidation process are as reported in the previous work [9].

\section{Model Formulation}

Experimental data obtained from the highlighted research work were used for the model derivation. Computational analysis of these data shown in Table 1, gave rise to Table 3 which indicate that; 


$$
\zeta-\mathrm{S}_{\mathrm{e}} \vartheta-\mathrm{S} \approx \mathrm{N} \vartheta^{3}-\mathrm{K} \vartheta^{2}+\mathrm{N}_{\mathrm{e}} \vartheta
$$

Introducing the values of $\mathrm{S}_{\mathrm{e}}, \mathrm{S}, \mathrm{N}, \mathrm{K}$ and $\mathrm{N}_{\mathrm{e}}$, into equation (4)

$$
\begin{gathered}
\zeta-0.0002 \S-0.0931=0.0077 \vartheta^{3}-0.1618 \vartheta^{2}+0.9345 \vartheta \\
\zeta=0.0077 \vartheta^{3}-0.1618 \vartheta^{2}+0.9345 \vartheta+0.0002 \Im+0.0931
\end{gathered}
$$

Where

$\zeta=$ Conc. of bioextracted $\mathrm{Fe}(\%)$

$(\wp)=$ As- beneficiated Fe content of the ore $(\%)$

$(\vartheta)$ = Initial bioleaching solution $\mathrm{pH}$

$\mathrm{S}_{\mathrm{e}}=0.0002, \mathrm{~S}=0.0931, \mathrm{~N}=0.0077, \mathrm{~K}=0.1618$ and $\mathrm{N}_{\mathrm{e}}=0.9345$ are

equalizing constant (determined using C-NIKBRAN [10])

Table 1: Variation of removed phosphorus concentration with initial bioleaching solution $\mathrm{pH}$ [9]

\begin{tabular}{|c|c|c|}
\hline$($ ( ) & $\mathrm{pH}$ & $(\zeta)$ \\
\hline 45.9 & 1 & 0.8 \\
45.9 & 2 & 1.5 \\
45.9 & 4 & 1.7 \\
45.9 & 7 & 1.3 \\
45.9 & 9 & 1.1 \\
45.9 & 13 & 1.9 \\
\hline
\end{tabular}

\section{Boundary and Initial Condition}

Consider iron ore (in a furnace) mixed with a culture of ATF. The atmosphere was not contaminated i.e (free of unwanted gases and dusts). Initially, atmospheric levels of oxygen are assumed just before the reaction between the ore and the microbes. Mass of iron oxide ore: $(50 \mathrm{~g})$, particle size: 0.25 mesh size, treatment time: 2 weeks, constant treatment temperature: $25^{\circ} \mathrm{C}$, range of initial bioleaching solution $\mathrm{pH}$ used; $1.0-13$.

The boundary conditions are: oxygen atmosphere at the top and bottom of the ore particles interacting with the microbes. At the bottom of the particles, a zero gradient for the gas scalar are assumed and also for the gas phase at the top of the particles. The reduced iron is stationary. The sides of the particles are taken to be symmetries.

\section{Model Validation}

\section{Results And Discussions}

The validity of the model is strongly rooted in equation (5) (core model equation) where both sides of the equation are correspondingly approximately equal. Table 3 also agrees with equation (5) following the values of $\zeta-0.0002 \&-0.0931$ and $0.0077 \vartheta^{3}-0.1618 \vartheta^{2}+0.9345 \vartheta$ evaluated from the experimental results in Table 1.

Table 3: Variation of $\zeta-0.0002 \S-0.0931$ with $0.0077 \vartheta^{3}-0.1618 \vartheta^{2}+0.9345 \vartheta$

\begin{tabular}{|l|l|}
\hline$\zeta-0.0002 \unlhd-0.0931$ & $0.0077 \vartheta^{3}-0.1618 \vartheta^{2}+0.9345 \vartheta$ \\
\hline 0.6978 & 0.7804 \\
1.3978 & 1.2834 \\
1.5978 & 1.6420 \\
1.1978 & 1.2544 \\
\hline
\end{tabular}

Furthermore, the derived model was validated by comparing the bioextracted Fe concentration predicted by the model and that obtained from the experiment. This was done using various evaluative techniques such as computational, statistical, graphical and deviational analysis.

\section{Computational Analysis}

Computational analysis of the experimental and model-predicted bioextracted Fe concentration was carried out to ascertain the degree of validity of the derived model. This was done by comparing bioextracted $\mathrm{Fe}$ per unit initial bioleaching solution $\mathrm{pH}$ valuated from model-predicted results with those from actual experimental results 
Bioextracted Fe concentration per unit initial bioleaching solution $\mathrm{pH} \zeta_{\mathrm{P}}(\%)$ was calculated from the equation;

$$
\zeta_{P}=\zeta / \vartheta
$$

Therefore, a plot of the concentration of bioextracted Fe against initial bioleaching solution $\mathrm{pH}$ as in Fig. 1 using experimental results in Table 1, gives a slope, $S$ at points $(1,0.8)$ and $(13,1.9)$ following their substitution into the mathematical expression;

$$
\zeta_{\mathrm{P}}=\Delta \zeta / \Delta \vartheta
$$

Equation (8) is detailed as

Where

$$
\zeta_{P}=\zeta_{2}-\zeta_{1} / \vartheta_{2}-\vartheta_{1}
$$

$\Delta \zeta=$ Change in bioextracted Fe concentrations of $\zeta_{2}, \zeta_{1}$ at two values of the initial bioleaching solution $\mathrm{pH} \vartheta_{2}, \vartheta_{1}$. Considering the points $(1,0.8)$ and $(13,1.9)$ for $\left(\vartheta_{1}, \zeta_{1}\right)$ and $\left(\vartheta_{2}, \zeta_{2}\right)$ respectively, and substituting them into equation $(9)$, gives the slope as $0.0917 \%$ which is the bioextracted Fe concentration per unit initial bioleaching solution $\mathrm{pH}$ during the actual leaching process.

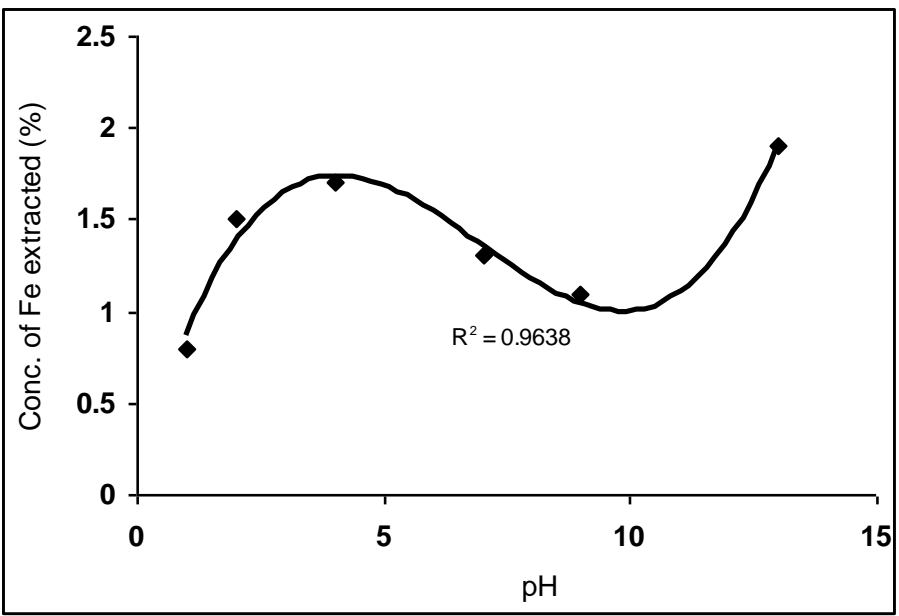

Fig. 1: Coefficient of determination between bioextracted Fe concentration and initial bioleaching solution $\mathrm{pH}$ as obtained from experiment [9]

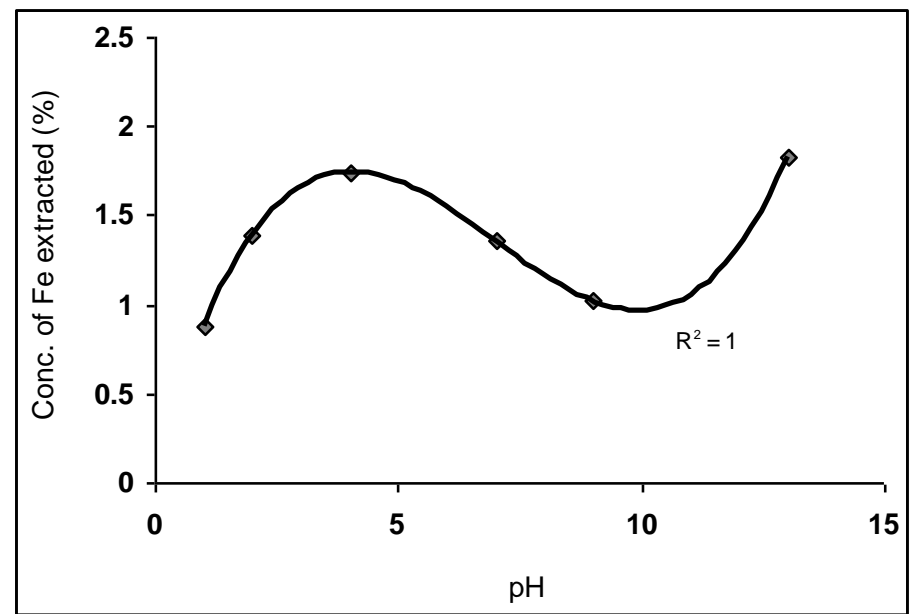

Fig. 2: Coefficient of determination between bioextracted Fe concentration and initial bioleaching solution $\mathrm{pH}$ as obtained from derived

Similarly a plot of the concentration of bioextracted Fe against ore particle size (as in Fig. 2) using derived model-predicted results gives a slope: $0.0784 \%$ on substituting the points $(1,0.8826)$ and $(13,1.8234)$ for $\left(\vartheta_{1}, \zeta_{1}\right)$ and $\left(\vartheta_{2}, \zeta_{2}\right)$ respectively into equation (9). This is the model-predicted bioextracted Fe concentration per unit initial bioleaching solution $\mathrm{pH}$. 


\section{Statistical Analysis}

The standard errors (STEYX) in predicting the bioextracted Fe concentration (using results from experiment and derived model) for each value of the initial bioleaching solution $\mathrm{pH}$ are 0.3917 and $0.3780 \%$ respectively. The standard error was evaluated using Microsoft Excel version 2003.

Considering the coefficient of determination $\mathrm{R}^{2}$ from Figs. 1 and 2, the correlations between bioextracted Fe concentration and initial bioleaching solution $\mathrm{pH}$ as obtained from experiment and derived model predicted results, was calculated using the equation;

$$
\mathrm{R}=\sqrt{ } \mathrm{R}^{2}
$$

The evaluations show correlations 0.9817 and 1.0000 respectively. These evaluated results indicate that the derived model predictions are significantly reliable and hence valid considering its proximate agreement with results from actual experiment.

\section{Graphical Analysis}

Comparative graphical analysis of Fig. 3 shows very close alignment of the curves from modelpredicted bioextracted $\mathrm{Fe}$ concentration $(\mathrm{MoD})$ and that of the experiment $(\mathrm{ExD})$. The degree of alignment of these curves is indicative of the proximate agreement between both experimental and model-predicted bioextracted Fe concentration.

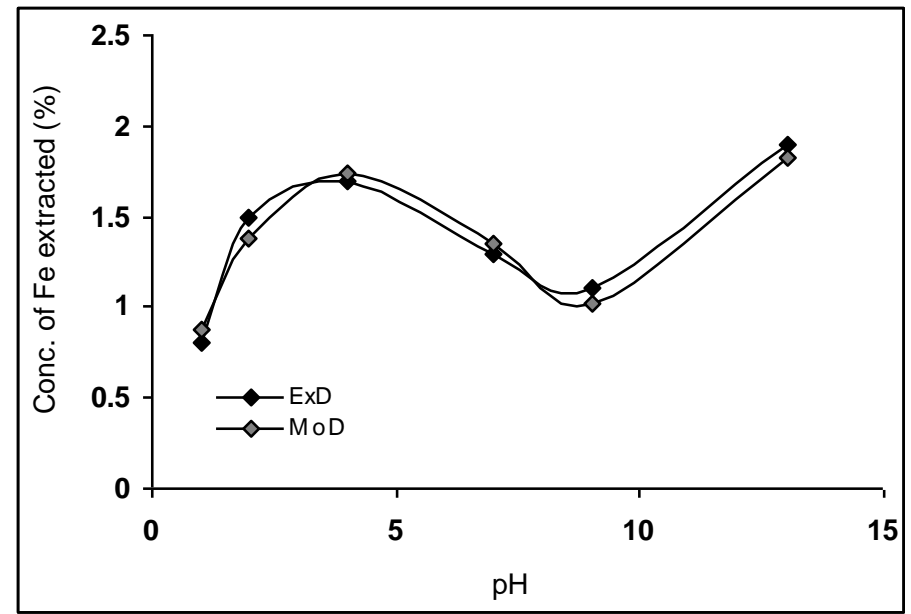

Fig. 3: Comparison of the bioextracted Fe concentrations (relative to initial bioleaching solution $\mathrm{pH}$ ) as obtained from experiment and derived model

\section{Deviational Analysis}

Analysis of bioextracted Fe concentrations from the experiment and derived model revealed deviations on the part of the model-predicted values relative to values obtained from the experiment. This is attributed to the fact that the surface properties of the iron ore and the physiochemical interactions between the ore and the microbes (ATF) which were found to have played vital roles during the process were not considered during the model formulation. This necessitated the introduction of correction factor, to bring the model-predicted bioextracted $\mathrm{Fe}$ concentration to those of the corresponding experimental values.

Deviation (Dn) of model-predicted bioextracted Fe concentration from that of the experiment is given by

$$
\mathrm{Dn}=\left[\frac{\boldsymbol{p}_{\mathrm{v}}-\mathrm{Ev}}{\mathrm{Ev}}\right] \times 100
$$

Where

$$
\mathrm{Pv}=\text { bioextracted Fe concentration as predicted by derived model }
$$

$\mathrm{Ev}=$ bioextracted $\mathrm{Fe}$ concentration as obtained from experiment

Correction factor $(\mathrm{Cr})$ is the negative of the deviation i.e

$$
\mathrm{Cr}=-\mathrm{Dn}
$$

Therefore 


$$
\mathrm{Cr}=-\left(\frac{\mathrm{Pv}_{\mathrm{v}}-\mathrm{Ev}}{\mathrm{Ev}}\right)^{\mathrm{d}} 100
$$

Introduction of the corresponding values of $\mathrm{Cr}$ from equation (13) into the derived model gives exactly the extracted iron concentration as obtained from experiment.

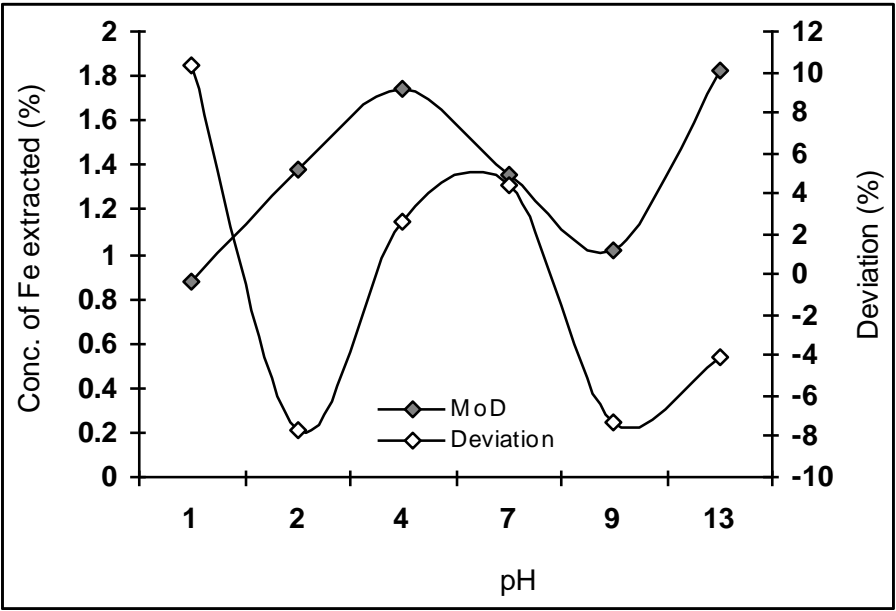

Fig. 4: Variation of model-predicted bioextracted Fe concentration with associated deviation from experimental results (relative to initial bioleaching solution $\mathrm{pH}$ )

Fig. 4 shows that the maximum deviation of the model-predicted bioextracted Fe concentration from the corresponding experimental values is less than $11 \%$. The figure shows that the least and highest magnitudes of deviation of the model-predicted bioextracted $\mathrm{Fe}$ concentration (from the corresponding experimental values) are +2.6 and $+10.33 \%$ which corresponds to bioextracted Fe concentrations: 1.7442 and $0.8826 \%$, as well as initial bioleaching solution $\mathrm{pH}$ : 4 and 1 respectively.

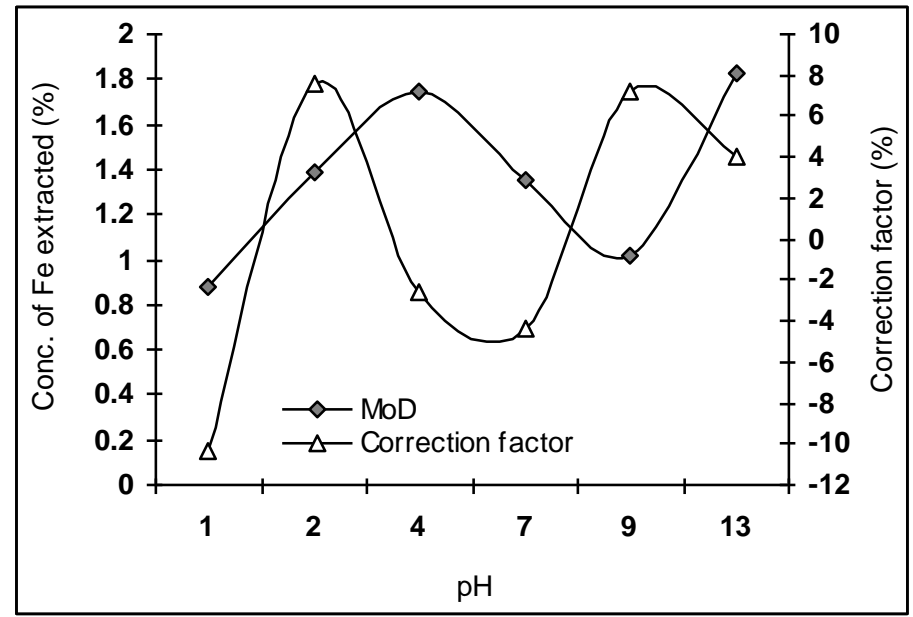

Fig. 5: Variation of model-predicted bioextracted Fe concentration with associated correction factor (relative to initial bioleaching solution $\mathrm{pH}$ )

Comparative analysis of Figs. 4 and 5 indicates that the orientation of the curve in Fig. 5 is opposite that of the deviation of model-predicted bioextracted Fe concentration (Fig. 4). This is because correction factor is the negative of the deviation as shown in equations (12) and (13). It is believed that the correction factor takes care of the effects of surface properties of the iron ore and the physiochemical interactions between the iron ore and microbes which have played vital roles during the process, but were not considered during the model formulation. Fig. 5 indicates that the least and highest magnitudes of correction factor to the model-predicted bioextracted Fe concentration are -2.6 and $-10.33 \%$ which corresponds to bioextracted $\mathrm{Fe}$ concentrations: 1.7442 and $0.8826 \%$, as well as initial bioleaching solution $\mathrm{pH}: 4$ and 1 respectively.

It is important to state that the deviation of model predicted results from that of the experiment is just the magnitude of the value. The associated sign preceding the value signifies that the deviation is a deficit (negative sign) or surplus (positive sign). 


\section{Conclusions}

Open system analysis of bioextracted iron was carried out during leaching of iron oxide ore using acidithiobacillus ferrooxidans. The analysis showed prediction of the concentration of bioextracted iron at varying initial bioleaching solution $\mathrm{pH}$ and as-beneficiated $\mathrm{Fe}$ content of the ore. An empirical model was derived, validated and used as a tool for the analysis. The validity of the polynomial model was rooted on the core expression $\zeta-0.0002 \&-0.0931=0.0077 \vartheta^{3}-0.1618 \vartheta^{2}+0.93459$ where both sides of the expression are correspondingly approximately equal. Statistical analysis of the extracted iron concentration as obtained from experiment and derived model for each value of the initial bioleaching solution $\mathrm{pH}$ used shows standard errors of 0.3917 and 0.3780 respectively. Extracted iron concentrations per unit initial bioleaching solution $\mathrm{pH}$ as obtained from experiment and derived model are 0.0917 and $0.0784 \%$ Deviational analysis indicates that the maximum deviation of the model-predicted iron extraction (from experimental results) was less than $11 \%$, implying a confidence level above $89 \%$.

\section{References}

[1] Taxiarchour, M., Panias, D., Doumi, I., Paspaliaris, I., Kontopoulos, A., (1997a) Removal of Iron from Silica Sand by Leaching with Oxalic Acid, Hydrometallurgy, 46, 215-227.

[2] Lee, S.O, Tran, T., Park Y.Y., Kim S.J., and Kim, M. J. (2006) Study on the Kinetics of Iron Leaching by Oxalic Acid.Int. J .Miner Process, 80, 144-152.

[3] Taxiarchou, M., Parnias, D., Doumi, I., Paspaliaris, I., and Kontopoulous, A. (1997a) Dissolution of Haematite in Acidic Oxalate Solutions. Hydrometallurgy, 44, 287-299.

[4] Panias, D., Taxiarchou, M., Paspaliaris, I., Kontopoulos, A. (1996) Mechanism of Dissolution of Iron Oxides in Aqueous Oxalic Acid. Hydrometallurgy, 42, 257-265.

[5] Lee, S. O., Oh, J. K., Shin, B. S. (1999) Dissolution of Iron Rust Materials using Oxalic Acid. J. Min. Metall. Inst. Jpn. 115, 815819. Alafara, A. Baba, D., Adekola, F. A., Folashade, A. O. (2005). Quantitative Leaching of a Nigerian Iron Ore in Hydrochloric Acid, J. Appl. Sci. Environ. Mgt. 9(3):15 - 20

[6] Nwoye, C. I., Amara, G. N., and Onyemaobi, O. O. (2008). Model for Evaluating Dissolved Iron during Leaching of Iron Oxide Ore in Sulphuric Acid Solution, Inter. J. Nat. Appl. Sc., 4(2): 209-211.

[7] Nwoye, C. I., Obasi, G. C., Mark, U., Inyama, S., Nwakwuo, C. C. (2009). Model for Calculating the Concentration of Leached Iron Relative to the Final Solution Temperature during Sulphuric Acid Leaching of Iron Oxide Ore. New York Science Journal, 2 (3):49-54.

[8] Nwoye, C. I., Ofoegbu, S. U., Obi, M. C., Nwakwuo, C. C. (2009). Model for Predictive Analysis of the Concentration of Dissolved Iron Relative to the Weight Input of Iron Oxide Ore and Leaching Temperature during Sulphuric Acid Leaching. Nature and Science Journal. 7(3):41-47.

[9] Ameh, E. M. (2013). Dephosphorization of Agbaja Iron Ore By Sintering And Bioleaching Processes. Ph.D Thesis, Nnamdi Azikiwe University Awka, Anambra State, Nigeria.

[10] Nwoye, C. I. (2008). C-NIKBRAN: Data Analytical Memory 